\title{
Soil Carbon Changes Influenced by Soil Management and Calculation Method
}

\author{
Maysoon M. Mikha ${ }^{1 *}$, Joseph G. Benjamin ${ }^{1}$, Ardell D. Halvorson ${ }^{2}$, David C. Nielsen ${ }^{1}$ \\ ${ }^{1}$ US Department of Agricultural, Agricultural Research Service, Central Great Research Station, Akron, USA; ${ }^{2}$ US Department of \\ Agricultural, Agricultural Research Service, Northern Plains Soil Plant Nutrient Research, Fort Collins, USA. \\ Email: *Maysoon.Mikha@ars.usda.gov
}

Received March 12 ${ }^{\text {th }}, 2013$; revised April 13 ${ }^{\text {th }}, 2013$; accepted April 21 $1^{\text {st }}, 2013$

Copyright (C) 2013 Maysoon M. Mikha et al. This is an open access article distributed under the Creative Commons Attribution License, which permits unrestricted use, distribution, and reproduction in any medium, provided the original work is properly cited.

\begin{abstract}
Throughout the years, many studies have evaluated changes in soil organic carbon (SOC) mass on a fixed-depth (FD) basis without considering changes in soil mass caused by changing bulk density $\left(\rho_{\mathrm{b}}\right)$. This study evaluates the temporal changes in SOC caused by two factors: 1) changing SOC concentration; and 2) changing equivalent soil mass (ESM) in comparison with FD. In addition, this study evaluates calculating changes in SOC stock over time using a minimum equivalent soil mass $\left(\mathrm{ESM}_{\min }\right)$ basis from a single sampling event compared with the FD scenario. A tillage [no-tillage (NT) and chisel plow (CP)]-crop rotation (multiple crop and continuous corn), and irrigation (full and delayed)) study was initiated in 2001 on Weld silt loam soil. After seven years, SOC concentration in the $0-30 \mathrm{~cm}$ depth was $19.7 \%$ greater in 2008 compared with 2001. Standardizing the soil mass of 2001 to the ESM of 2008 for each individual treatment showed an average gain in SOC of $5.8 \mathrm{Mg} \mathrm{C} \cdot \mathrm{ha}^{-1}$ in 2008 compared with 2001. However, the increase in SOC using ESM was twice the SOC gained with the FD calculation, where some treatments lost SOC after seven years of management. Estimating SOC levels using the $\mathrm{ESM}_{\min }$ and, thereby, eliminating the confounding effect of soil $\rho_{\mathrm{b}}$ indicated that SOC stock was influenced by crop species and their interaction with irrigation, but not by tillage practices. Over all, the ESM calculation appears to be more effective in evaluating SOC stock than the FD calculation.
\end{abstract}

Keywords: Soil Organic Carbon Stock; Equivalent Soil Mass; Minimum Equivalent Soil Mass; Fixed-Depth; Management Practices

\section{Introduction}

Numerous studies [1-8] have assessed management practice-induced changes in SOC due to anthropogenic and environmental effects. The majority of previous research [1-6] evaluated SOC mass using SOC concentration and soil bulk density $\left(\rho_{\mathrm{b}}\right)$ associated with a specific soil depth. However, management practices that influence SOC concentration may also affect soil $\rho_{\mathrm{b}}$ [5,9-12]. Consequently, researchers have argued that changes in soil $\rho_{\mathrm{b}}$ and its effect on unequal soil mass associated with the fixed depth have a confounding effect on SOC mass estimation when comparing changes in SOC associated with different management practices [13-17]. With an acknowledgment that SOC storage depends on soil mass and soil $\rho_{\mathrm{b}}$, recent research estimated SOC and other soil nutrients based on their concentration, soil thickness, and soil $\rho_{\mathrm{b}}$ [13-18]. Researchers have suggested alternative

\footnotetext{
"Corresponding author.
}

methods to calculate SOC and other soil nutrients to account for the changes in soil volume under different management practices $[13,14,16]$.

The equivalent soil mass (ESM) is one of the methods being used to assess SOC and other soil nutrients on a normalized soil mass per unit area basis to account for differences in soil masses caused by soil management [13-16,18]. In the ESM calculation scenario, soil masses associated with different management practices are standardized to a particular soil mass per unit area of a specified layer and the equivalent soil $\mathrm{C}$ mass is adjusted to the ESM $[13,16,19]$. The goal of using the ESM and its associated equivalent $\mathrm{C}$ mass calculation is to reduce the SOC error calculated in soil profiles due to changing soil $\rho_{\mathrm{b}}$ under different management practices $[13,16]$. Lee et $a l$. [16] proposed two other scenarios for SOC estimation associated with a single sampling event when the initial SOC or initial $\left(\rho_{\mathrm{b}}\right)$ values were not available. The first method was based on using the minimum equivalent soil 
mass $\left(\mathrm{ESM}_{\min }\right)$ measured and the second alternative measurement was based on using the maximum equivalent soil mass $\left(\mathrm{ESM}_{\max }\right)$ measured. The $\mathrm{ESM}_{\min }$ uses the lowest soil mass measured, on an FD basis, to standardize other soil masses associated with different management practices. The $\mathrm{ESM}_{\max }$ uses the greatest soil mass measured, on an FD basis, among the different management practices as the standard [16].

The concept of soil mass and expressing SOC on an equivalent mass basis has been adopted by researchers for more than a decade, but this approach has not been readily applied to evaluate different management practices $[13,16]$. There has been limited research on the influence of different management practices on the standardized soil $\rho_{\mathrm{b}}$, soil mass, and the associated SOC using field measured SOC and soil $\rho_{\mathrm{b}}$. This type of research is vital due to the fact that, in recent years, there has been a great interest for evaluating SOC stock and improving soil $\mathrm{C}$ sequestration as influenced by different management practices. Preventing SOC losses due to soil management practices, especially tillage, and increasing crop residue return to the soil are important parameters in improving soil quality and sustainability. However, the confounding effect of soil $\rho_{\mathrm{b}}$ variability and the accuracy the soil $\rho_{\mathrm{b}}$ measurement are influencing the perceived temporal changes in SOC stock or SOC content in any given sampling period.

This study aims to evaluate different scenarios of SOC calculation where the confounding effect of soil $\rho_{\mathrm{b}}$ variability and its associated soil mass could be eliminated or reduced. We hypothesize that eliminating the differences in soil $\rho_{\mathrm{b}}$ and standardizing the soil masses into an ESM basis may be more effective in predicting the temporal changes in SOC stock or in SOC content at any given time period compared with FD scenario. Therefore, the objectives of this study were to: 1) evaluate the temporal changes in SOC concentration to eliminate the temporal variation in soil $\left.\rho_{\mathrm{b}} ; 2\right)$ evaluate the temporal changes in SOC stock as influenced by the FD and the ESM calculation methods; and 3) evaluate treatment effects on SOC using the $\mathrm{ESM}_{\text {min }}$ basis of standardization. Overall, this study identifies the temporal changes in SOC stock as influenced by different calculation scenarios after seven years of different management practices and subsequent changes in soil $\rho_{\mathrm{b}}$ and soil mass.

\section{Materials and Methods ${ }^{1}$}

\subsection{Site Description}

An irrigation-tillage-crop rotation study was established

${ }^{1}$ Mention of commercial products and organization in this paper is solely to provide specific information. It does not constitute endorsement by USDA-ARS over other products and organization not mentioned. The US Department of Agriculture, Agricultural Research Service, is an equal opportunity/affirmative action employer and all agency services are available without discrimination. in 2001 with an individual plot size of $18 \mathrm{~m} \times 9 \mathrm{~m}$ at the USDA-ARS Central Great Plains Research Station near Akron, CO [6]. The research station is located within a semiarid climate region with approximate mean annual precipitation of $418 \mathrm{~mm}$. The study site is located at $40^{\circ} 8^{\prime} \mathrm{N}$ latitude and, $103^{\circ} 9^{\prime} \mathrm{W}$ longitude with elevation of $1384 \mathrm{~m}$. The soil type is a Weld silt loam (fine, smectitic, mesic Aridic Argiustolls). Treatments were arranged in a split-plot design with three replications. The main plot was an irrigation treatment and the subplot was the tillage and crop system that were randomized within the main irrigation plots. Details of tillage practices, irrigation treatment, previous and current cropping history, and site management were reported in detail by Benjamin et al. [6]. Briefly, tillage treatments included NT (directly planting into the previous crop residues; no-till) and $\mathrm{CP}$ (fall chisel plow at $35 \mathrm{~cm}$ depth with a parabolic-shank deep ripper and spring pass with a mulch treader disrupting the approximately $0-5 \mathrm{~cm}$ depth). The irrigation treatment consisted of either full or delayed irrigation. The crop system treatments consisted of either continuous corn (CC) or a rotation (Rot) of a variety of crops throughout the study period, red kidney bean (Phaseolus vulgaris L.), spring barley (Hordeum vulgare L.), sunflower (Helianthus annuus L.), corn (Zea mays L.), spring pea (Pisum sativum L.), winter wheat (Triticum aestivum L.).

\subsection{Soil Sampling}

Soil samples were collected from non-wheel-tracked areas from the $0-15$ and $15-30 \mathrm{~cm}$ depths in the spring of 2001 and 2008 before planting. The soil samples were collected from each plot using a $5 \mathrm{~cm}$ diam. probe attached to a Giddings hydraulic soil sampler (Giddings Machine Co., Windsor, CO). Soil samples were stored in sterile polypropylene bags placed coolers during field sampling and then stored at $4^{\circ} \mathrm{C}$ in a walk-in cooler for about a week before processing. Soil samples were prescreened through a $2 \mathrm{~mm}$ sieve to remove large pieces of plant material before being air dried and ground to pass through a $2 \mathrm{~mm}$ screen using a flail-type soil grinder. Soil samples for determining soil bulk density $\left(\rho_{\mathrm{b}}\right)$ were also collected at the same sampling dates in 2001 and 2008. Soil $\rho_{\mathrm{b}}$ samples were collected for each plot using a 7.5 $\mathrm{cm}$ diam. by $60 \mathrm{~cm}$ long probe containing $7.5 \mathrm{~cm}$ diam. by $7.5 \mathrm{~cm}$ deep aluminum rings. The probe was attached to a Giddings hydraulic soil sampler for insertion into the soil. The rings were sectioned in the field to ensure an undisturbed soil sample with depth. Data were averaged for the $0-15 \mathrm{~cm}$ and $15-30 \mathrm{~cm}$ depths used in this study.

\subsection{Soil Total C, Soil Inorganic C, and Soil Organic Carbon}

Three subsamples per sampling bag were composited, 
ground to pass a $150 \mu$ screen, and analyzed for different forms of soil carbon. Soil total C (STC) contents from the $0-15$ and $15-30 \mathrm{~cm}$ depth were determined by dry combustion using a Carlo Erba C-N analyzer (Haake Buchler Instruments, Inc., Saddle Brook, NJ) at a commercial lab (Ward Laboratories, Kearney, NE). Soil inorganic C (SIC) content was evaluated using a modified pressure-calcimeter method reported by Sherrod et al. [20]. Soil organic C (SOC) content was calculated from the differences between STC and SIC. The SOC at $0-30$ $\mathrm{cm}$ depth presented in this study is a sum of SOC associated with $0-15$ and $15-30 \mathrm{~cm}$ depths. Data at $0-15$ and $15-30 \mathrm{~cm}$ depths for SOC on a fixed depth basis were explained in details by Benjamin et al. [6].

\subsection{Expression of Soil Organic Carbon (SOC)}

The SOC associated with an ESM was calculated using the approach outlined by Ellert and Bettany [13] and Lee et al. [16]. The calculations presented in this study represent three scenarios for SOC evaluation. The first scenario estimates the temporal changes only in SOC concentration $\left(\mathrm{g} \cdot \mathrm{C} \cdot \mathrm{kg}^{-1}\right.$ soil) from 2001 to 2008 (Table 1).
The second scenario estimates the temporal changes in SOC stock from 2001 to 2008 adjusted to the ESM of 2008 for every treatment combination in the $0-30 \mathrm{~cm}$ depth. The third scenario evaluates treatment effects on SOC after 7 yrs of differing management practices adjusted to the $\mathrm{ESM}_{\text {min }}$ as if there was a single sampling in 2008. In addition, changes in SOC in the $0-30 \mathrm{~cm}$ depth using the second calculation scenario (ESM) will be compared to SOC calculated by the FD method reported by Benjamin et al. [6].

\subsection{Equivalent Soil Mass (ESM) Scenario}

To evaluate the temporal changes in SOC stock between 2001 and 2008 in the $0-30 \mathrm{~cm}$ depth, soil mass of 2001 was adjusted to the soil mass of 2008 (ESM) as influenced by management practices. In 2001, soil at this study site exhibited a high bulk density, ranging between 1.46 to $1.51 \mathrm{Mg} \cdot \mathrm{m}^{-3}$ at the $0-30 \mathrm{~cm}$ depth. In 2008, soil bulk density at the $0-30 \mathrm{~cm}$ depth ranged between 1.21 to $1.37 \mathrm{Mg} \cdot \mathrm{m}^{-3}$ (Table 2). The soil mass in 2008 associated with each treatment was considered the baseline for the ESM calculation.

Table 1. The 2001 and 2008 soil organic C (SOC) concentration $\left(\mathrm{g} \cdot \mathrm{kg}^{-1}\right)$ and the changes in SOC from 2001 to 2008 at $0-30 \mathrm{~cm}$ depth as influenced by irrigation, cropping, and tillage practices.

\begin{tabular}{|c|c|c|c|c|c|}
\hline Irrigation & Tillage & Cropping & SOC 2001 & SOC 2008 & $\Delta \operatorname{SOC}^{\mathrm{a}} 2008-2001$ \\
\hline & & & --------' & -- $0-30 \mathrm{~cm}$ & ------------------------ \\
\hline Full & $\mathrm{NT}^{\mathrm{b}}$ & $\mathrm{CC}^{\mathrm{c}}$ & 8.47 & 10.03 & 1.56 \\
\hline Full & $\mathrm{CP}$ & $\mathrm{CC}$ & 8.29 & 9.61 & 1.32 \\
\hline Delayed & NT & $\mathrm{CC}$ & 7.05 & 9.42 & 2.37 \\
\hline Delayed & $\mathrm{CP}$ & $\mathrm{CC}$ & 7.01 & 8.97 & 1.96 \\
\hline Full & NT & Rot & 7.91 & 9.00 & 1.09 \\
\hline Full & $\mathrm{CP}$ & Rot & 7.75 & 8.67 & 0.92 \\
\hline Delayed & NT & Rot & 7.60 & 8.60 & 1.00 \\
\hline Delayed & $\mathrm{CP}$ & Rot & 7.50 & 9.43 & 1.93 \\
\hline Irrigation (I) & & & 0.08 & 0.27 & 0.22 \\
\hline Cropping (Cr) & & & 0.95 & 0.004 & 0.074 \\
\hline Tillage $(\mathrm{T})$ & & & 0.67 & 0.56 & 0.94 \\
\hline $\mathrm{I} \times \mathrm{Cr}$ & & & 0.07 & 0.028 & 0.64 \\
\hline $\mathrm{I} \times \mathrm{T}$ & & & 0.86 & 0.13 & 0.53 \\
\hline $\mathrm{Cr} \times \mathrm{T}$ & & & 0.98 & 0.049 & 0.24 \\
\hline $\mathrm{I} \times \mathrm{Cr} \times \mathrm{T}$ & & & 0.94 & 0.07 & 0.28 \\
\hline
\end{tabular}

${ }^{\mathrm{a}} \Delta \mathrm{SOC}=$ Changes in SOC concentration from 2001 to $2008 ;{ }^{\mathrm{b}} \mathrm{NT}=$ No-tillage $; \mathrm{CP}=$ Chisel plow; ${ }^{\mathrm{c}} \mathrm{CC}=$ Continuous corn; Rot $=$ Mixed grass and broadleaf crops. 


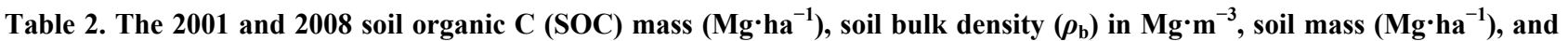
changes in SOC from 2001 to 2008 at $0-30 \mathrm{~cm}$ depth evaluated on a fixed depth (FD) basis and on an equivalent soil mass of the $2008\left(\mathrm{ESM}_{2008}\right)$ as influenced by irrigation, cropping, and tillage practices.

\begin{tabular}{|c|c|c|c|c|c|c|c|c|c|c|c|}
\hline \multirow[b]{3}{*}{ Irrigation } & \multirow[b]{3}{*}{ Tillage } & \multirow[b]{3}{*}{ Cropping } & \multicolumn{7}{|c|}{ 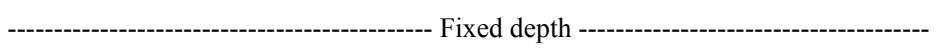 } & \multicolumn{2}{|c|}{----- $\mathrm{ESM}_{2008}$----- } \\
\hline & & & \multicolumn{2}{|c|}{------- SOC --------- } & \multicolumn{2}{|c|}{---------- $\rho_{\mathrm{b}}$---------- } & \multicolumn{2}{|c|}{--- Soil mass ---- } & \multirow{2}{*}{$\frac{\Delta \mathrm{SOC}^{\mathrm{a}}}{2008-2001}$} & \multirow{2}{*}{$\begin{array}{l}\text { SOC } \\
2001\end{array}$} & \multirow{2}{*}{$\frac{\Delta \mathrm{SOC}^{\mathrm{b}}}{2008-2001}$} \\
\hline & & & 2001 & 2008 & 2001 & 2008 & 2001 & 2008 & & & \\
\hline & & & \multicolumn{9}{|c|}{ 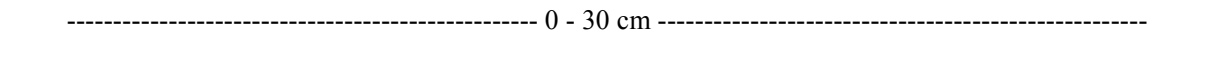 } \\
\hline & & & \multicolumn{2}{|c|}{------ Mg·ha ${ }^{-1}------$} & \multicolumn{2}{|c|}{----- $\mathrm{Mg} \cdot \mathrm{m}^{-3}$----- } & \multicolumn{5}{|c|}{ 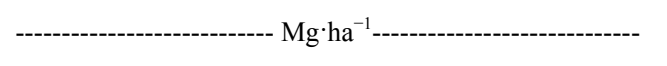 } \\
\hline Full & $\mathrm{NT}^{\mathrm{c}}$ & $\mathrm{CC}^{\mathrm{d}}$ & $38.3 \mathrm{a}^{\mathrm{e}}$ & $41.4 \mathrm{a}$ & $1.505 \mathrm{a}$ & $1.370 \mathrm{a}$ & $4515 \mathrm{a}$ & $4110 \mathrm{a}$ & $3.2 \mathrm{a}$ & $34.88 \mathrm{a}$ & $6.5 \mathrm{a}$ \\
\hline Full & $\mathrm{CP}$ & $\mathrm{CC}$ & $37.0 \mathrm{a}$ & $36.5 \mathrm{a}$ & $1.481 \mathrm{ab}$ & $1.270 \mathrm{a}$ & $4443 a b$ & $3810 \mathrm{a}$ & $-0.5 \mathrm{a}$ & $31.58 \mathrm{a}$ & $4.9 \mathrm{a}$ \\
\hline Delayed & NT & $\mathrm{CC}$ & $31.1 \mathrm{a}$ & $37.3 \mathrm{a}$ & $1.464 \mathrm{~b}$ & $1.313 \mathrm{a}$ & $4392 \mathrm{~b}$ & 3939 a & $6.2 \mathrm{a}$ & $27.78 \mathrm{a}$ & $9.5 \mathrm{a}$ \\
\hline Delayed & $\mathrm{CP}$ & $\mathrm{CC}$ & $31.0 \mathrm{a}$ & $32.3 \mathrm{a}$ & $1.477 \mathrm{ab}$ & $1.208 \mathrm{a}$ & $4431 \mathrm{ab}$ & $3624 \mathrm{a}$ & $1.3 \mathrm{a}$ & $25.41 \mathrm{a}$ & $6.9 \mathrm{a}$ \\
\hline Full & NT & Rot & $35.2 \mathrm{a}$ & $34.6 \mathrm{a}$ & $1.485 \mathrm{ab}$ & $1.295 \mathrm{a}$ & $4455 \mathrm{ab}$ & $3885 \mathrm{a}$ & $-0.6 \mathrm{a}$ & $30.72 \mathrm{a}$ & $3.9 \mathrm{a}$ \\
\hline Full & $\mathrm{CP}$ & Rot & $34.5 \mathrm{a}$ & $31.5 \mathrm{a}$ & $1.483 \mathrm{~b}$ & $1.213 \mathrm{a}$ & $4449 a b$ & $3639 a$ & $-2.9 \mathrm{a}$ & $28.18 \mathrm{a}$ & $3.3 \mathrm{a}$ \\
\hline Delayed & NT & Rot & $33.9 \mathrm{a}$ & $32.1 \mathrm{a}$ & $1.500 \mathrm{a}$ & $1.242 \mathrm{a}$ & $4500 \mathrm{a}$ & $3727 \mathrm{a}$ & $-1.8 \mathrm{a}$ & $28.32 \mathrm{a}$ & $3.8 \mathrm{a}$ \\
\hline Delayed & $\mathrm{CP}$ & Rot & $32.7 \mathrm{a}$ & $34.6 \mathrm{a}$ & $1.463 \mathrm{~b}$ & $1.226 \mathrm{a}$ & $4389 \mathrm{ab}$ & $3678 \mathrm{a}$ & $1.9 \mathrm{a}$ & $27.72 \mathrm{a}$ & $7.0 \mathrm{a}$ \\
\hline \multicolumn{2}{|c|}{ Irrigation (I) } & & 0.08 & 0.10 & 0.45 & 0.17 & 0.47 & 0.17 & 0.61 & 0.08 & 0.26 \\
\hline \multicolumn{2}{|c|}{ Cropping $(\mathrm{Cr})$} & & 0.94 & 0.0007 & 0.88 & 0.004 & 0.87 & 0.006 & 0.02 & 0.34 & 0.07 \\
\hline \multicolumn{2}{|c|}{ Tillage (T) } & & 0.51 & 0.02 & 0.17 & 0.003 & 0.19 & 0.004 & 0.16 & 0.14 & 0.85 \\
\hline \multicolumn{2}{|c|}{$\mathrm{I} \times \mathrm{Cr}$} & & 0.06 & 0.01 & 0.16 & 0.13 & 0.17 & 0.15 & 0.87 & 0.06 & 0.70 \\
\hline \multicolumn{2}{|c|}{$\mathrm{I} \times \mathrm{T}$} & & 0.83 & 0.07 & 0.87 & 0.33 & 0.96 & 0.28 & 0.67 & 0.60 & 0.53 \\
\hline \multicolumn{2}{|c|}{$\mathrm{Cr} \times \mathrm{T}$} & & 0.89 & 0.01 & 0.29 & 0.06 & 0.30 & 0.06 & 0.18 & 0.63 & 0.20 \\
\hline \multicolumn{2}{|c|}{$\mathrm{I} \times \mathrm{Cr} \times \mathrm{T}$} & & 0.68 & 0.06 & 0.02 & 0.20 & 0.02 & 0.19 & 0.36 & 0.86 & 0.29 \\
\hline
\end{tabular}

${ }^{\mathrm{a}} \Delta \mathrm{SOC}=$ Changes in SOC from 2001 to 2008 calculated on a fixed depth basis (FD) as reported by [6]; ${ }^{\mathrm{b}} \Delta \mathrm{SOC}=\mathrm{Changes}$ in SOC from 2001 calculated on $\mathrm{ESM}_{2008}$ basis to 2008 calculated on a fixed depth basis; ${ }^{\mathrm{c}} \mathrm{NT}=$ No-tillage; $\mathrm{CP}=$ Chisel plow; ${ }^{\mathrm{d}} \mathrm{CC}=\mathrm{Continuous}$ corn; Rot $=$ mixed grass and broadleaf crops; ${ }^{\mathrm{e}}$ Different letter represents significant $(\mathrm{P}<0.05)$ differences among the treatments within the same measurement and year.

Soil masses for each treatment in 2001 and 2008 were calculated on an FD basis using soil depth at $0-30 \mathrm{~cm}$ and field measured bulk density (Table 2) as

$$
\mathrm{M}_{\text {soil }}=\mathrm{d} \times \rho_{\mathrm{b}} \times 10^{-4}
$$

where $\mathrm{M}_{\text {soil }}$ represents soil mass measured in $\left(\mathrm{Mg} \cdot \mathrm{ha}^{-1}\right)$, $\mathrm{d}$ represents soil depth measured in $(\mathrm{m}), \rho_{\mathrm{b}}$ represents soil bulk density measured in $\left(\mathrm{Mg} \cdot \mathrm{m}^{-3}\right)$ at the $\mathrm{FD}$, and $10^{4}$ is the conversion factor $\left(\mathrm{m}^{2} \cdot \mathrm{ha}^{-1}\right)$. The SOC mass for the FD of $0-30 \mathrm{~cm}$ was calculated from field measured SOC concentration as

$$
\mathrm{M}_{\mathrm{C}}=\mathrm{M}_{\text {soil }} \times \mathrm{C}_{\text {cons }} \times 10^{-3}
$$

where $\mathrm{M}_{\mathrm{C}}$ represents soil $\mathrm{C}$ mass $\left(\mathrm{Mg} \cdot \mathrm{C} \cdot \mathrm{ha}^{-1}\right)$ at the fixed-depth, $\mathrm{C}_{\text {cons }}$ represents SOC concentration $\left(\mathrm{kg} \cdot \mathrm{Mg}^{-1}\right)$, and $10^{-3}$ is the conversion factor $\left(\mathrm{Mg} \cdot \mathrm{kg}^{-1}\right)$.

To account for the difference in soil masses and bulk densities between 2001 and 2008, the soil mass and as- sociated SOC in 2001 were adjusted to the ESM determine in 2008 using a calculation procedure similar to Ellert and Bettany [13] and Lee et al. [16]. The equivalent soil mass for each treatment (i) $\left[\mathrm{ESM}_{(\mathrm{i})}\right]$ in 2008 was considered to be the baseline soil mass in 2001 for the same treatment. For each treatment (i) in 2001, the SOC content on an $\mathrm{ESM}_{(\mathrm{i})}$ basis was calculated as shown in Figure 1. The example calculation in Figure 1 represents the data from the first treatment in Table 2 in the $0-30$ cm depth, Full irrigation with NT and continuous corn (CC) cropping system. In this example, the soil mass in 2001 at $0-30 \mathrm{~cm}$ depth on a FD basis was reduced by $405 \mathrm{Mg} \cdot \mathrm{ha}^{-1}$ due to different management practices compared with the baseline of the same treatment (4110 $\mathrm{Mg} \cdot \mathrm{ha}^{-1}$ ) in 2008 (Table 2), calculated as

$$
\mathrm{M}_{\text {sub(i) }}=\mathrm{M}_{\text {soil(2001)(i) }}-\mathrm{ESM}_{(\mathrm{i})}
$$

where $M_{\text {sub(i) }}$ represents the soil mass subtracted from 


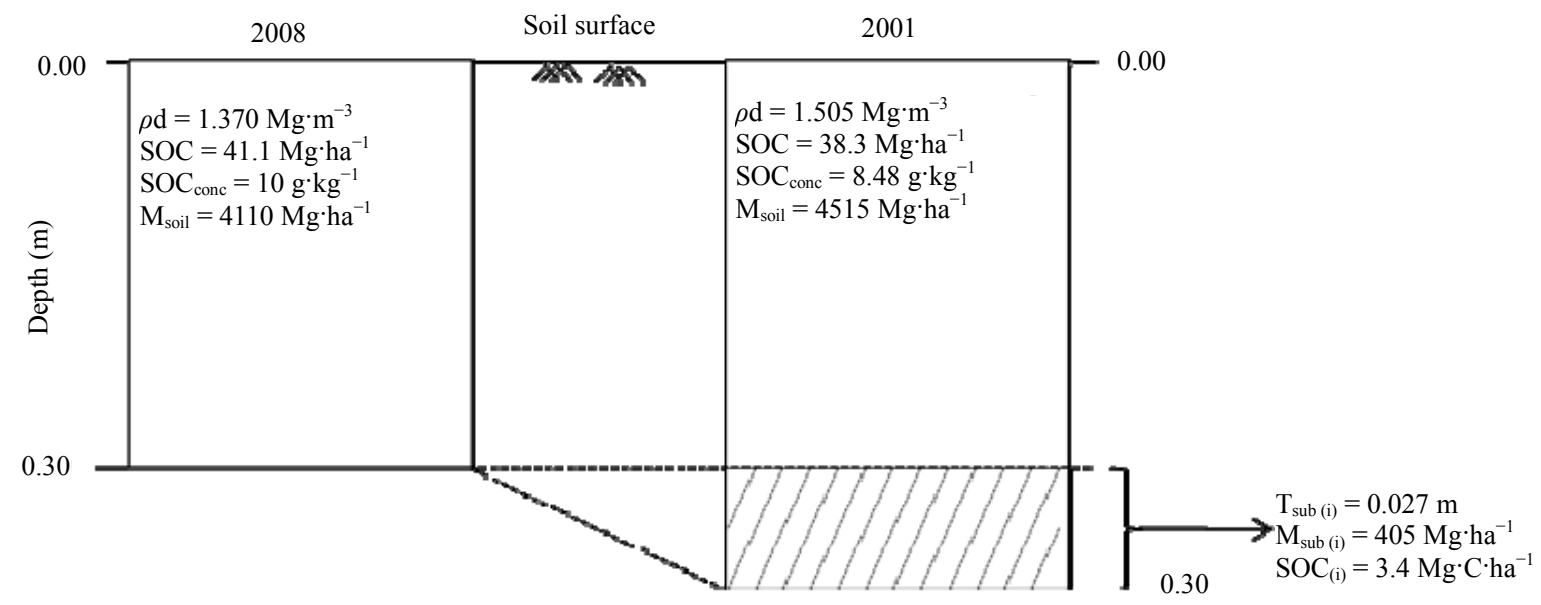

Figure 1. Example calculation for 2001 soil organic C (SOC) on an equivalent soil mass (ESM) basis of the 2008 soil mass at 0 - $30 \mathrm{~cm}$ depth. $\mathrm{M}_{\text {soil }}$ represents soil mass in $\mathrm{Mg}^{\cdot} \cdot \mathrm{ha}^{-1}$ on a fixed-depth basis (FD) for 2001 and 2008, $\rho_{\mathrm{b}}$ represents soil bulk

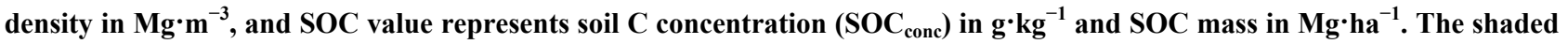

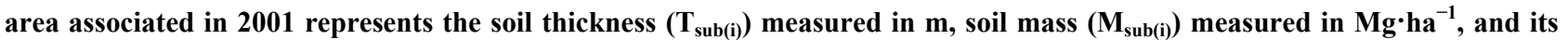
corresponding $\mathrm{SOC}_{(\mathrm{i})}$ measured in $\mathrm{Mg} \cdot \mathrm{ha}^{-1}$ that needs to be subtracted from the 2001 value associated with the treatment (i) to standardized to the 2008 soil masses.

$2001\left(\mathrm{Mg} \cdot \mathrm{ha}^{-1}\right)$ for specific treatment (i), $\mathrm{M}_{\text {soil (2001) (i) }}$

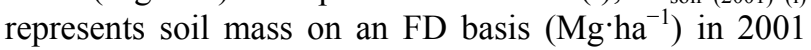
associated with a specific treatment (i), $\mathrm{ESM}_{(\mathrm{i})}$ represents

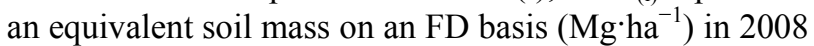
associated with the same specific treatment (i). The SOC associated with the subtracted layer of 2001 was equivalent to $3.4 \mathrm{Mg} \cdot \mathrm{ha}^{-1}$ and was calculated using SOC concentration following Equation (2). Therefore, the SOC in 2001 was reduced to $\sim 34.9 \mathrm{Mg} \cdot \mathrm{ha}^{-1}$ to adjust to the $\mathrm{ESM}_{(\mathrm{i})}$ for the same treatment (Table 2). In addition, as the soil mass of treatment (i) in 2001 was reduced, the soil thickness in 2001 for the same treatment was also reduced. The specific soil thickness $(0.02691 \mathrm{~m})$ associated with $\mathrm{M}_{\text {sub(i) }}$ was also subtracted from $30 \mathrm{~cm}$ depth in 2001 (Figure 1) calculated as follows:

$$
\mathrm{T}_{\text {sub }(\mathrm{i})}=\frac{\mathrm{M}_{\mathrm{sub}(\mathrm{i})}}{\rho_{\mathrm{b}(2001)(\mathrm{i})}} \times 10^{-4}
$$

where $T_{\text {sub(i) }}$ represents the soil thickness (m) that needs to be subtracted from 2001 for a specific treatment (i), $M_{\text {sub(i) }}$ represents the soil mass subtracted from 2001 $\left(\mathrm{Mg} \cdot \mathrm{ha}^{-1}\right)$ to adjust to the soil mass of 2008 for a specific treatment (i), $\rho_{\mathrm{b}}$ (2001) (i) represents the 2001 bulk density $\left(\mathrm{Mg} \cdot \mathrm{m}^{-3}\right)$ of treatment (i), and $10^{-4}$ represents the conversion factors $\left(\mathrm{ha} \cdot \mathrm{m}^{-2}\right)$.

\subsection{Minimum Equivalent Soil Mass Basis $\left(\mathbf{E S M}_{\min }\right)$ Scenario}

To estimate changes in SOC in 2008 among different management practices in the $0-30 \mathrm{~cm}$ depth, SOC was evaluated on the $\mathrm{ESM}_{\min }$ as proposed by Lee et al. [16].
This type of SOC evaluation can be used when the initial conditions (SOC or bulk density) are not available. In this method, all soil masses associated with different treatments will be adjusted to the minimum observed soil mass and its associated $\rho_{\mathrm{b}}$ measured in 2008 in the $0-30$ cm depth. The ESM $\mathrm{Em}_{\text {min }}$ chosen from the 2008 was 3624 $\mathrm{Mg} \cdot \mathrm{ha}^{-1}$ that represents the minimum $\rho_{\mathrm{b}}$ (Table 2). In this approach, since the minimum soil mass was chosen, a specific amount of soil mass, with its associated SOC, was subtracted from each treatment in 2008 to equal the $\mathrm{ESM}_{\text {min }}$ (Table 3). For each treatment in 2008, the SOC on an $\mathrm{ESM}_{\text {min }}$ basis was calculated as in Equation (1) and Equation (2), except that $\mathrm{M}_{\text {sub(i) }}$ was calculated as

$$
\mathrm{M}_{\text {sub(i) }}=\mathrm{M}_{\text {soil(i) }}-\mathrm{ESM}_{\min }
$$

where $M_{\text {sub(i) }}$ represents the soil mass subtracted $\left(\mathrm{Mg} \mathrm{ha}^{-1}\right)$ from each treatment (i) in 2008, $\mathrm{M}_{\text {soil(2008)(i) }}$ represents soil mass on an FD basis $\left(\mathrm{Mg} \cdot \mathrm{ha}^{-1}\right)$ in 2008 associated with a specific treatment (i), and $\mathrm{ESM}_{\text {min }}$ represents the

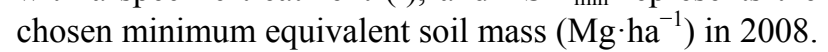
The specific soil thickness associated with $\mathrm{M}_{\text {sub(i) }}$ was also subtracted from $30 \mathrm{~cm}$ depth in 2008 calculated as follows:

$$
\mathrm{T}_{\text {sub(i) }}=\frac{\mathrm{M}_{\text {sub(i) }}}{\rho_{\mathrm{b}(\mathrm{i})}} \times 10^{-4}
$$

where $\mathrm{T}_{\text {sub(i) }}$ represents the soil thickness (m) that needs to be subtracted from a specific treatment (i) in 2008 , $\mathrm{M}_{\text {sub(i) }}$ represents the soil mass subtracted from 2008 $\left(\mathrm{Mg} \cdot \mathrm{ha}^{-1}\right)$ to adjust to the $\mathrm{ESM}_{\text {min }}, \rho_{\mathrm{b} \text { (i) }}$ represents the 2008 bulk density $\left(\mathrm{Mg} \cdot \mathrm{m}^{-3}\right)$ of treatment (i), and $10^{-4}$ represents the conversion factors $\left(\mathrm{ha} \cdot \mathrm{m}^{-2}\right)$. 


\subsection{Statistical Analyses}

Analyses of variance were calculated using SAS Version 9.2 [21] to determine statistically significant effects of irrigation, tillage, and crop system on SOC content. The data were analyzed as a split plot design, with irrigation being the main effect and the factorial tillage and crop rotation treatments being sub plots within the main plots. The F-test was used to evaluate the treatment factors main effects and interactions. An F-protected t-test was used on a pair-wise comparison to follow up any significant findings. All results were considered significantly different at $p<0.05$ unless noted otherwise.

\section{Results and Discussions}

\subsection{Soil Organic Carbon on the Concentration Basis}

The first scenario, where SOC and changes in SOC are presented on a concentration basis $\left(\mathrm{g} \cdot \mathrm{C} \cdot \mathrm{kg}^{-1}\right.$ soil $)$ is used to eliminate the temporal variation and the error associated with soil $\rho_{\mathrm{b}}$ measurements $[22,23]$. This scenario could be used as an option if the temporal changes in soil $\rho_{\mathrm{b}}$ are high or if the soil $\rho_{\mathrm{b}}$ was not measured.

Average SOC in the $0-30 \mathrm{~cm}$ depth, expressed on a concentration basis, was $19.7 \%$ greater in 2008 compared with 2001 (Table 1). These data also show that SOC concentration was higher in 2008 than 2001 for every treatment combination, indicating that all management practices improved SOC at this study site. There were no treatment differences in SOC concentrations in 2001, because 2001 represents the initial condition for this study. However, SOC in 2008 was influenced by cropping system $(\mathrm{p}=0.004)$, where SOC associated with CC system was $6.5 \%$ greater than the Rot system. All treatments gained SOC between 2001 and 2008, and the increase ranged between 0.13 to $0.34 \mathrm{~g} \cdot \mathrm{kg}^{-1} \cdot \mathrm{yr}^{-1}$ (Table 1). The increase of SOC with CC plots was, on average 23\%, where the increase of the Rot plots was 16\%.

\subsection{Soil Organic Carbon Stocks on the Equivalent Soil Mass of 2008 Basis (ESM)}

Soil $\rho_{\mathrm{b}}$ in the $0-30 \mathrm{~cm}$ depth significantly decreased with time $(\mathrm{p}<0.0001)$ by an average of $14.6 \%$ in 2008 compared with 2001 (Table 2). Averaged across all the treatment combinations, there was insignificant change in SOC, as evaluated by the FD basis, between 2008 and 2001. The SOC in the CC cropping system increased an average $7.4 \%$, compared with an average of $2.3 \%$ with Rot system. Benjamin et al. [6] also concluded that SOC, measured on an FD basis, in NT plots gained an average of $2.1 \mathrm{Mg} \cdot \mathrm{ha}^{-1}$, whereas the CP plots lost an average of $0.1 \mathrm{Mg} \cdot \mathrm{ha}^{-1}$ at the 0 - to $30-\mathrm{cm}$ soil depth during the seven-year study period. Many researchers argue the fact that changes in soil $\rho_{\mathrm{b}}$, and its effect on unequal soil mass associated with the FD, has a confounding effect on the SOC mass estimation [12-14,16,17]. The changes in $\rho_{\mathrm{b}}$ between 2001 and 2008 (Table 2) influenced soil mass, $\mathrm{SOC}$, and the temporal change in SOC in the $0-30 \mathrm{~cm}$ layer, calculated on a fixed-depth basis. The principle behind the ESM calculation scenario is to evaluate the temporal changes in SOC mass by eliminating the changes in soil $\rho_{\mathrm{b}}$ caused by time and different management practices. In this scenario, the soil masses of 2001 were standardized to the soil masses of 2008 for each treatment. The decision to normalize soil mass of 2001 to the mass of 2008 was influenced by two facts: 1) the soil $\rho_{\mathrm{b}}$ and, consequently, the soil masses associated with 2001 were higher than 2008; and 2) no soil samples were measured below $30 \mathrm{~cm}$ depth, which provided no additional information about soil $\rho_{\mathrm{b}}$ and SOC below $30 \mathrm{~cm}$ for the 2008 sampling period. This is important because to adjust the low soil mass of 2008 to the high soil mass of 2001, a specific soil mass and SOC need to be added to soil mass of 2008 from the layer below $30 \mathrm{~cm}$.

The reduction in soil masses from 2001 to 2008 ranged between $405 \mathrm{Mg} \cdot \mathrm{ha}^{-1}$ to $810 \mathrm{Mg} \cdot \mathrm{ha}^{-1}$. Likewise, the reduction in SOC from 2001 to 2008 ranged between 3.3 $\mathrm{Mg} \cdot \mathrm{ha}^{-1}$ to $6.3 \mathrm{Mg} \cdot \mathrm{ha}^{-1}$ (Table 2). Using ESM as the calculation scenario showed that management practices throughout the seven year period significantly $(\mathrm{p}<$ 0.0001 ) increased SOC by an average of $19.7 \%$ in 2008 compared with 2001. The NT plots gained an average of $5.9 \mathrm{Mg} \cdot \mathrm{ha}^{-1}$ of SOC, whereas the CP plots gained an average of $5.6 \mathrm{Mg} \cdot \mathrm{ha}^{-1}$ of SOC between 2008 and 2001. Similarly, the CC treatment gained an average of $21 \%$ SOC, and the Rot plots gained an average of $16 \%$ SOC between 2008 and 2001. In fact, SOC stock and percent SOC increased over time calculated with this scenario are similar to what we observed previously when SOC was evaluated on a concentration basis.

Using the ESM scenario produced SOC increases in all of the treatments between 2001 and 2008. The SOC gained with this scenario was parallel to what we previously observed with SOC measured on a concentration basis. However, the SOC change between 2001 and 2008 with the ESM calculation scenario averaged 0.47 to 1.36 $\mathrm{Mg} \mathrm{C} \mathrm{ha}{ }^{-1} \cdot \mathrm{yr}^{-1}$, compared with that of Benjamin et al. [6], which averaged -0.41 to $0.89 \mathrm{Mg} \cdot \mathrm{C} \cdot \mathrm{ha}^{-1} \cdot \mathrm{yr}^{-1}$, (Table 2). Apparently, the soil $\rho_{\mathrm{b}}$ in both time periods had a confounding effect on the changes in how SOC was evaluated. These data agree with our hypothesis that normalizing the soil mass of 2001 to the ESM of 2008 for each treatment reduced the confounding effect of a changing soil $\rho_{\mathrm{b}}$. Also these data revealed that different soil management practices affected SOC status at this study site. 


\subsection{Soil Organic Carbon Stocks on the Minimum Equivalent Soil Mass Basis $\left(\mathrm{ESM}_{\text {min }}\right)$}

The minimum equivalent soil mass $\left(\mathrm{ESM}_{\min }\right)$ is an approach for estimating SOC levels when the initial data were not previously measured [16]. The $\mathrm{ESM}_{\min }$ approach is useful when soil $\rho_{\mathrm{b}}$ has decreased with time. In this method, all soil masses from different management practices are standardized to the lowest soil mass and lowest $\rho_{\mathrm{b}}$ across the treatments of interest. The lowest soil mass sampled in 2008, averaged across replications, was $3624 \mathrm{Mg} \cdot \mathrm{ha}^{-1}$ (Table 3), and, therefore, was considered the $\mathrm{ESM}_{\min }$. The $\mathrm{ESM}_{\text {min }}$ was observed with delayed irrigation with $\mathrm{CP}$ tillage and $\mathrm{CC}$ rotation. Since the $\mathrm{ESM}_{\min }$ was the lowest soil mass compared with any other treatment, the soil mass and associated SOC were subtracted from the $0-30 \mathrm{~cm}$ from all other treatments to adjust for $\mathrm{ESM}_{\text {min }}$.

In this scenario, the soil masses were reduced by an average of $0.0 \mathrm{Mg} \cdot \mathrm{ha}^{-1}$ to $486 \mathrm{Mg} \cdot \mathrm{ha}^{-1}$ compared to soil masses calculated on an FD basis (Table 3). The reduction in soil mass, after the $\mathrm{ESM}_{\min }$ adjustment, was greater with NT practice $\left(300 \mathrm{Mg} \cdot \mathrm{ha}^{-1}\right)$ and CC system $\left(246 \mathrm{Mg}^{-1} \mathrm{ha}^{-1}\right)$ compared with CP practice $\left(73 \mathrm{Mg}^{-h^{-1}}\right)$ and Rot system $\left(127 \mathrm{Mg}^{\cdot} \mathrm{ha}^{-1}\right)$. The greater amount of soil mass that was subtracted from NT practice was a consequence of higher soil $\rho_{\mathrm{b}}$ compared with CP practice (Table 2). After 7 yr of NT, soil $\rho_{\mathrm{b}}$ was $6.5 \%$ greater $(\mathrm{p}=$ 0.003) in those plots than in the CP plots, which may be due to yearly soil disturbance associated with $\mathrm{CP}$ treatment. Adjusting the soil masses to the $\mathrm{ESM}_{\text {min }}$ reduced

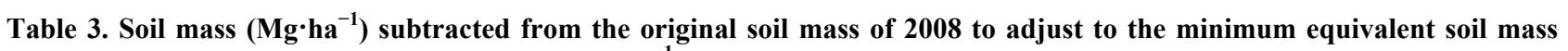

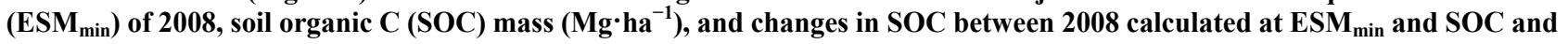
on a fixed depth (FD) basis at $0-30 \mathrm{~cm}$ depth as influenced by irrigation, cropping system, and tillage practices.

\begin{tabular}{|c|c|c|c|c|c|}
\hline \multirow[b]{2}{*}{ Irrigation } & \multirow[b]{2}{*}{ Tillage } & \multirow[b]{2}{*}{ Cropping } & \multicolumn{2}{|c|}{ 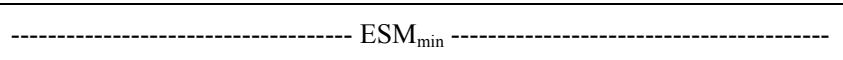 } & \multirow{2}{*}{$\frac{\Delta \mathrm{SOC}_{2008}{ }^{\mathrm{b}}}{\mathrm{ESM}_{\min }-\mathrm{FD}}$} \\
\hline & & & Soil mass subtracted ${ }^{\mathrm{a}}$ & SOC & \\
\hline & & & ---------------------------- & 30 cm---------------- & --------------- \\
\hline & & & ---- & Mg ha $^{-1}------------$ & 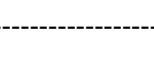 \\
\hline Full & $\mathrm{NT}^{\mathrm{c}}$ & $\mathrm{CC}^{\mathrm{d}}$ & 486 & 36.3 & -5.1 \\
\hline Full & $\mathrm{CP}$ & $\mathrm{CC}$ & 186 & 34.8 & -1.7 \\
\hline Delayed & NT & $\mathrm{CC}$ & 315 & 34.1 & -3.2 \\
\hline Delayed & $\mathrm{CP}$ & $\mathrm{CC}$ & 0 & 32.3 & 0.0 \\
\hline Full & NT & Rot & 261 & 32.6 & -2.0 \\
\hline Full & $\mathrm{CP}$ & Rot & 15 & 31.4 & -0.1 \\
\hline Delayed & NT & Rot & 102 & 31.2 & -1.0 \\
\hline Delayed & $\mathrm{CP}$ & Rot & 54 & 34.2 & -0.4 \\
\hline \multicolumn{3}{|c|}{ Equivalent soil mass } & $3624^{\mathrm{e}}$ & & \\
\hline \multicolumn{2}{|c|}{ Irrigation (I) } & & 0.12 & 0.29 & 0.13 \\
\hline \multicolumn{2}{|c|}{ Cropping (Cr) } & & 0.009 & 0.007 & 0.004 \\
\hline \multicolumn{2}{|c|}{ Tillage (T) } & & 0.003 & 0.59 & 0.004 \\
\hline \multicolumn{2}{|c|}{$\mathrm{I} \times \mathrm{Cr}$} & & 0.09 & 0.039 & 0.09 \\
\hline \multicolumn{2}{|c|}{$\mathrm{I} \times \mathrm{T}$} & & 0.42 & 0.16 & 0.19 \\
\hline \multicolumn{2}{|c|}{$\mathrm{Cr} \times \mathrm{T}$} & & 0.048 & 0.64 & 0.039 \\
\hline \multicolumn{2}{|c|}{$\mathrm{I} \times \mathrm{Cr} \times \mathrm{T}$} & & 0.30 & 0.09 & 0.33 \\
\hline
\end{tabular}

${ }^{\text {a }}$ Soil mass subtracted from the original soil mass of 2008 at $0-30 \mathrm{~cm}$ to adjust to the minimum equivalent soil mass $\left.\left(\mathrm{ESM}_{\min }\right) \mathrm{basis}_{(\mathrm{Table}} \mathbf{1}\right) ;{ }^{\mathrm{b}} \Delta \mathrm{SOC}_{2008}=$ changes in SOC between $\mathrm{ESM}_{\min }$ (presented in this table) and SOC on a fixed depth basis (Table 1) at $0-30 \mathrm{~cm}$ depth; ${ }^{\mathrm{c}} \mathrm{NT}=\mathrm{No}-\mathrm{tillage}$; CP $=\mathrm{Chisel}$ plow; ${ }^{\mathrm{d}} \mathrm{CC}$ $=$ continuous corn; Rot $=$ mixed grass and broadleaf crops; ${ }^{\mathrm{e}}$ Minimum equivalent soil mass $\left(\mathrm{ESM}_{\min }\right)$ represents the lowest soil mass in $2008(\mathrm{Table} 1)$ used to adjust the mass of the other treatments at $0-30 \mathrm{~cm}$ depth. 
SOC an average of $0.0 \mathrm{Mg} \cdot \mathrm{ha}^{-1}$ to $5.1 \mathrm{Mg} \cdot \mathrm{ha}^{-1}$ (Table 3). The reduction in SOC was influenced by tillage $(\mathrm{p}=$ $0.004)$, cropping system $(\mathrm{p}=0.004)$, and the two way interaction of tillage $\mathrm{x}$ cropping system $(\mathrm{p}=0.039)$. Eliminating the variability of soil $\rho_{\mathrm{b}}$ by adjusting the soil masses associated with different treatment combinations to an $\mathrm{ESM}_{\min }$ reduced the influence of tillage practices (Tables 2 and 3) on changes in SOC. The differences in SOC between tillage practices disappeared because a significant amount of SOC was subtracted from the NT practices to adjust all treatments to the $\mathrm{ESM}_{\text {min }}$ standard. SOC evaluated on an $\mathrm{ESM}_{\text {min }}$ basis was $4.8 \%$ lower $(\mathrm{p}=$ 0.005 ) than SOC evaluated on an FD basis. However, the effect of cropping system and the two way interaction, irrigation $\mathrm{x}$ cropping system, had the same influence on SOC (Tables 2 and 3) calculated with $\mathrm{ESM}_{\min }$ and FD scenarios. Apparently, standardizing soil masses to an $\mathrm{ESM}_{\text {min }}$ eliminated the influence of tillage practices on SOC evaluation. These data agree with our previous hypothesis that evaluating SOC from a single sampling event on an $\mathrm{ESM}_{\min }$ was more effective compared with FD scenario basis due to the elimination of the soil $\rho_{\mathrm{b}}$ variation associated with different management practices.

It is important to recognize that there is another scenario of SOC calculation based on a maximum equivalent soil mass $\left(\mathrm{ESM}_{\max }\right)$ proposed by Lee et al. [16] for SOC changes from a single sampling event. Briefly, the $\mathrm{ESM}_{\max }$ is based on using the greatest soil mass, on the fixed-depth basis, among the different management practices to which the other soil masses were normalized [16]. A specific soil mass, soil thickness, and its associated SOC are then added to the treatment that exhibits smaller soil mass than $\mathrm{ESM}_{\max }$ chosen. The $\mathrm{ESM}_{\max }$ calculation scenario may give us a different perspective of SOC influenced by different management practices, but this type of calculation was not performed for this data set due to the sampling depth limitations In this study, the lack of available SOC information associated with soil below 30 $\mathrm{cm}$ depth made it difficult to adjust soil masses to the $\mathrm{ESM}_{\text {max }}$.

\section{Conclusion}

Evaluation of the temporal changes in SOC stock was influenced by calculation scenarios as a consequence of changes in soil $\rho_{\mathrm{b}}$. The SOC estimation depends on how one calculates changes in soil mass associated with different sampling periods or management practices. Changes in SOC evaluated on the FD basis could be influenced by soil $\rho_{\mathrm{b}}$ variability. The temporal changes in the percent SOC gained when using the ESM calculation scenario were similar to what we observed when SOC change was calculated on a concentration basis. These data indicate that the ESM was more effective in evaluating SOC stock due to the similarity to the temporal changes in
SOC concentration compared with the FD scenario. The $\mathrm{ESM}_{\text {min }}$ method appears to be an effective scenario for SOC evaluation from a single sampling event. We were unable to compare the $\mathrm{ESM}_{\text {min }}$ method with other evaluation scenarios due to the sampling depth limitations. Therefore, it is advisable to sample several centimeters below the chosen depth of interest to allow for SOC evaluation with different scenarios. Over all, the ESM scenario, where the temporal changes in soil $\rho_{\mathrm{b}}$ and soil mass were adjusted for each individual treatment, appears to be an effective scenario for evaluating SOC changes under these study conditions. We recommend, however, that the FD scenario also be included in future SOC evaluations so that comparisons with historical studies on changes in SOC with management and time can be made.

\section{REFERENCES}

[1] G. A. Peterson, A. D. Halvorson, J. L. Havlin, O. R. Jones, D. J. Lyon and D. L. Tanaka, "Reduced Tillage and Increasing Cropping Intensity in the Great Plains Conserves Soil C," Soil and Tillage Research, Vol. 47, No. 3-4, 1998, pp. 207-218. doi:10.1016/S0167-1987(98)00107-X

[2] A. D. Halvorson, G. A. Peterson and C. A. Reule, "Tillage System and Crop Rotation Effects on Dryland Crop Yield and Soil Carbon in the Central Great Plains," Agronomy Journal, Vol. 94, No. 6, 2002, pp. 1429-1436. doi:10.2134/agronj2002.1429

[3] M. M. Mikha and C. W. Rice, "Tillage and Manure Effects on Soil and Aggregate-Associated Carbon and Nitrogen," Soil Science Society of American Journal, Vol. 68, No. 3, 2004, pp. 809-816. doi:10.2136/sssaj2004.0809

[4] K. A. McVay, J. A. Budde, K. Fabrizzi, M. M. Mikha, C. W. Rice, A. J. Schlegel, D. E. Peterson, D. W. Sweeney and C. Thompson, "Management Effects on Soil Physical Properties in Long-Term Tillage Studies in Kansas," Soil Science Society of American Journal, Vol. 70, No. 2, 2006, pp. 434-438. doi:10.2136/sssaj2005.0249

[5] M. M. Mikha, M. F. Vigil, M. A. Liebig, R. A. Bowman, B. McConkey, E. J. Deibert and J. L. Pikul Jr., "Cropping System Influences on Soil Chemical Properties and Soil Quality in the Great Plains," Renewable Agricultural and Food System, Vol. 21, No. 1, 2006, pp. 26-35. doi:10.1079/RAFS2005123

[6] J. G. Benjamin, A. D. Halvorson, D. C. Nielsen and M. M. Mikha, "Crop Management Effects on Crop Residue Production and Changes in Soil Organic Carbon in the Central Great Plains," Agronomy Journal, Vol. 102, No. 3, 2010, pp. 990-997. doi:10.2134/agronj2009.0483

[7] C. P. Jantalia and A. D. Halvorson, "Nitrogen Fertilizer Effects on Irrigated Conventional Tillage Corn Yields and Soil Carbon and Nitrogen Pools," Agronomy Journal, Vol. 103, No. 3, 2011, pp. 871-878. doi:10.2134/agronj2010.0455

[8] A. D. Halvorson and C. P. Jantalia, "Nitrogen Fertilization Effects on Irrigated No-Till Corn Production and Soil 
Carbon and Nitrogen," Agronomy Journal, Vol. 103, No. 5, 2011, pp. 1423-1431. doi:10.2134/agronj2011.0102

[9] A. D. Halvorson, C. A. Reule and R. F. Follett, "Nitrogen Fertilization Effects on Soil Carbon and Nitrogen in a Dryland Cropping System," Soil Science Society of American Journal, Vol. 63, No. 4, 1999, pp. 912-917. doi:10.2136/sssaj1999.634912x

[10] J. A. Amador, Y. Wang, M. C. Savin and J. H. Görres, "Fine-Scale Spatial Variability of Physical and Biological Soil Properties in Kingston, Rhode Island," Geoderma, Vol. 98, No. 1-2, 2000, pp. 83-94. doi:10.1016/S0016-7061(00)00053-7

[11] J. G. Benjamin, M. M. Mikha, A. D. Nielsen, M. F. Vigil, F. Calderon and W. B. Henry, "Cropping Intensity Effects on Physical Properties of No-Till Silt Loam," Soil Science Society of American Journal, Vol. 71, No. 4, 2007, pp. 1160-1165. doi:10.2136/sssaj2006.0363

[12] M. M. Mikha, M. F. Vigil and J. G. Benjamin, "LongTerm Tillage Impacts on Soil Aggregation and Carbon Dynamics under Wheat-Fallow in the Central Great Plains," Soil Science Society of American Journal, Vol. 77, No. 2, 2013, pp. 594-605. doi:10.2136/sssaj2012.0125

[13] B. H. Ellert and J. R. Bettany, "Calculation of Organic Matter and Nutrients Stored in Soil under Contrasting Management Regimes," Canadian Society of Soil Science, Vol. 75, No, 4, 1995, pp. 529-538. doi:10.4141/cjss95-075

[14] X.-M. Yang and M. M. Wander, "Tillage Effects on Soil Organic Carbon Distribution and Storage in a Silt Loam Soil in Illinois," Soil and Tillage Research, Vol. 52, No. 1-2, 1999, pp. 1-9. doi:10.1016/S0167-1987(99)00051-3

[15] R. M. Gifford and N. L. Roderick, "Soil Carbon Stocks and Bulk Density: Special or Cumulative Mass Coordinates as a Basis for Expression?" Global Change Biology, Vol. 9, No. 11, 2003, pp. 1507-1514. doi:10.1046/j.1365-2486.2003.00677.x
[16] J. Lee, J. W. Hopmans, D. E. Rolston, S. G. Baer and J. Six, "Determining Soil Carbon Stock Changes: Simple Bulk Density Fail," Agriculture, Ecosystems and Environment, Vol. 134, No. 3-4, 2009, pp. 251-256. doi:10.1016/j.agee.2009.07.006

[17] S. B Wuest, "Correction of Bulk Density and Sampling Method Biases Using Soil Mass per Unit Area," Soil Science Society of American Journal, Vol. 73, No. 1, 2009, pp. 312-316. doi:10.2136/sssaj2008.0063

[18] A. Gál, T. J. Vyn, E. Michéli, E. J. Kladivko and W. W. McFee, "Soil Carbon and Nitrogen Accumulation with Long-Term No-Till Versus Mouldboard Plowing Overestimated with Tilled-Zone Sampling Depths," Soil and Tillage Research, Vol. 96, No. 1-2, 2007, pp. 42-51. doi:10.1016/j.still.2007.02.007

[19] B. H. Ellert, H. H. Janzen and B. G. McConkey, "Measuring and Comparing Soil Carbon Storage," In: R. Lal, Ed., Assessment Methods for Soil Carbon, Lewis Publishers, CRC Press, Boca Raton, 2001, pp. 131-144.

[20] L. A. Sherrod, G. Dunn, G. A. Peterson and R. L. Kolberg, "Inorganic Carbon Analysis by Modified PressureCalcimeter Method," Soil Science Society of American Journal, Vol. 66, No. 1, 2002, pp. 299-305. doi:10.2136/sssaj2002.0299

[21] R. C. Littell, G. A. Milliken, W. W. Stroup, R. D. Wolfinger and O. Schabenberger, "SAS for Mixed Models," SAS Institute Inc., Cary, 2006.

[22] S. D. Logsdon and C. A. Cambardella, "Temporal Changes in Small Depth-Incremental Soil Bulk Density," Soil Science Society of American Journal, Vol. 64, No. 2, 2000, pp. 710-714. doi: $10.2136 /$ sssaj2000.642710x

[23] A. Kulmatiski and K. H. Beard, "Reducing Sampling Error in Soil Research," Soil Biology and Biochemistry, Vol. 36, No. 2, 2004, pp. 383-385. doi:10.1016/j.soilbio.2003.10.004 